Abstract

\title{
Non-Alcoholic Ready-to-Drink Beverages in New Zealand: Snapshot of Availability, Serve Size and Sugar Content in $2019^{+}$
}

\author{
Teresa Castro ${ }^{1,2}$, Sally Mackay 1,*, Helen Eyles ${ }^{1,3}$, Leanne Young ${ }^{3}$ and Cliona Ni Mhurchu ${ }^{3}$ \\ 1 Department of Epidemiology and Biostatistics, The University of Auckland, Auckland 1142, New Zealand; \\ t.castro@auckland.ac.nz (T.C.); h.eyles@auckland.ac.nz (H.E.) \\ 2 Nutrition Section, The University of Auckland, Auckland 1010, New Zealand \\ 3 National Institute for Health Innovation, The University of Auckland, Auckland 1142, New Zealand; \\ leanne.young@auckland.ac.nz (L.Y.); c.nimhurchu@auckland.ac.nz (C.N.M.) \\ * Correspondence: sally.mackay@auckland.ac.nz; Tel.: +64-21-0242-6760 \\ + Presented at the 2019 Annual Meeting of the Nutrition Society of New Zealand, Napier, New Zealand, \\ 28-29 November 2019.
}

Published: 13 December 2019

Free sugars, particularly from beverages, are a major contributor to the growing burden of dietrelated diseases. We aimed to describe the types of non-alcoholic ready-to-drink beverages available for sale in New Zealand (NZ) in 2019, and their serving size and sugar contents.

Data on the availability, serve size and sugar contents of single serve beverages (serving size $=1$ and packet size $<600 \mathrm{~mL}$ ) were obtained from Nutritrack, an annually updated brand-specific food composition database. Beverages were classified into seven groups based on total sugar contents and presence of added sugars. Outcomes examined were: mean (SD) total sugar contents $(\mathrm{g} / 100 \mathrm{~mL})$, proportion of beverages sweetened with added sugars, proportion with serving size $<250 \mathrm{~mL}$, and proportion that would be liable for the UK Soft Drinks Industry Levy $(>5 \&<8 \mathrm{~g}$ and $>8 \mathrm{~g}$ sugar/100 $\mathrm{mL})$. ANOVA and Tukey post-hoc tests were applied for comparisons of means $(p<0.05)$.

We found that most available beverages were sweetened with added sugars $(66.5 \%, 260 / 391)$. Only $18.9 \%$ had a serve size $<250 \mathrm{~mL}$. Sugar sweetened waters and electrolyte, energy and soft drinks had a lower mean (SD) total sugar content 7.92 (3.6) g/100 mL than sweetened fruit juices/drinks 9.55 (3.4) $\mathrm{g} / 100 \mathrm{~mL}$ and similar mean total sugar content to sweetened flavoured dairy, plant-based milks, drinking yoghurts and breakfast beverages $8.46(2.2) \mathrm{g} / 100 \mathrm{~mL}$. Overall, $69.9 \%$ of sugar-sweetened beverages in NZ would be liable for the UK soft drinks levy: (97.6\% energy drinks; $100 \%$ electrolyte drinks; $66.7 \%$ soft drinks; $0 \%$ waters with added sugars; and $96.4 \%$ fruit juices/drinks with added sugars).

To summarize, two thirds of beverages available for sale in NZ supermarkets in 2019 were sweetened with added sugars, four fifths had serve sizes $>250 \mathrm{~mL}$, and almost three quarters would be taxed if a tax similar to the UK Soft Drinks Industry Levy was implemented. 